\title{
First genome sequencing and comparative analyses of Corynebacterium pseudotuberculosis strains from Mexico
}

\author{
Doglas Parise ${ }^{1 \dagger}$, Mariana T D Parise ${ }^{1 \dagger}$, Marcus V C Viana ${ }^{1}$, Adrian V Muñoz-Bucio², Yazmin A Cortés-Pérez ${ }^{2}$, \\ Beatriz Arellano-Reynoso ${ }^{2}$, Efrén Díaz-Aparicio² ${ }^{2}$ Fernanda A Dorella ${ }^{3}$, Felipe L Pereira ${ }^{3}$, Alex F Carvalho³, \\ Henrique C P Figueiredo ${ }^{3}$, Preetam Ghosh ${ }^{4}$, Debmalya Barh ${ }^{1,5,6}$, Anne C P Gomide ${ }^{1}$ and Vasco A C Azevedo ${ }^{1 *}$
}

\begin{abstract}
Corynebacterium pseudotuberculosis is a pathogenic bacterium which has been rapidly spreading all over the world, causing economic losses in the agricultural sector and sporadically infecting humans. Six C. pseudotuberculosis strains were isolated from goats, sheep, and horses with distinct abscess locations. For the first time, Mexican genomes of this bacterium were sequenced and studied in silico. All strains were sequenced using lon Personal Genome Machine sequencer, assembled using Newbler and SPAdes software. The automatic genome annotation was done using the software RAST and in-house scripts for transference, followed by manual curation using Artemis software and BLAST against NCBI and UniProt databases. The six genomes are publicly available in NCBI database. The analysis of nucleotide sequence similarity and the generated phylogenetic tree led to the observation that the Mexican strains are more similar between strains from the same host, but the genetic structure is probably more influenced by transportation of animals between farms than host preference. Also, a putative drug target was predicted and in silico analysis of 46 strains showed two gene clusters capable of differentiating the biovars equi and ovis: Restriction Modification system and CRISPR-Cas cluster.
\end{abstract}

Keywords: Phylogenetics, Genomic sequencing, Drug target, CRISPR-Cas, Restriction-modification systems

\section{Introduction}

Corynebacterium pseudotuberculosis is a Gram-positive bacterium that infects several different species of mammals. Strains of the biovar ovis infect sheep and goats, and strains of the biovar equi infect larger mammals such as horses, camels, and buffaloes. The manifestation of the infection depends on the host [1-4]. This bacterium causes significant economic loss to animal production all over the world due to reduced production of wool, milk and meat, carcass condemnation, as well as the death of infected animals [4-6]. C. pseudotuberculosis can also affect humans, causing distinct kinds of lymphadenitis. Contamination occurs through contact with infected animals and consumption of infected food $[4,5,7]$.

\footnotetext{
* Correspondence: vasco@icb.ufmg.br

${ }^{\dagger}$ Doglas Parise and Mariana T D Parise contributed equally to this work.

${ }^{1}$ Laboratory of Cellular and Molecular Genetics, Institute of Biologic Sciences,

Federal University of Minas Gerais, Belo Horizonte, MG, Brazil

Full list of author information is available at the end of the article
}

This organism affects several countries such as Australia, Brazil, Canada, Egypt, Israel, New Zealand, South Africa, United Kingdom and United States [4, 8-17]. Cases in other countries such as Portugal [18], Mexico [19] and Equatorial Guinea [20] have been reported in the recent years. In the United States, C. pseudotuberculosis infections are reemerging and considered endemic [19], and the state with the highest number of cases of this bacterium was Texas, which borders Mexico [21]. The spread of $C$. pseudotuberculosis to other countries brings out the importance of improving the understanding of this bacterium. In the present study, six Mexican C. pseudotuberculosis strains were investigated, two from the biovar equi and four from the biovar ovis. This is the first time that strains of this bacterium, isolated in Mexico, have been completely sequenced. Among those strains, these are the first isolates of the biovar equi coming from this country [19]. The characterization of these strains is important for achieving a better understanding of this species, 
considering they can present relevant features not yet identified in other strains.

\section{Organism information}

C. pseudotuberculosis is a pathogenic bacterium that belongs to the CMNR (Corynebacterium, Mycobacterium, Nocardia, and Rhodococcus) group. This group is characterized by high GC content (46-74\%) and by the structure of the cell wall which is mainly composed of peptidoglycan, arabinogalactan and mycolic acids [4, 22]. C. pseudotuberculosis is placed in the phylum Actinobacteria, class Actinobacteria, order Actinomycetales, suborder Corynebacterineae and genus Corynebacterium [23-30]. The species is considered a facultative intracellular pathogen $[4,31]$ which is Gram-positive, pleomorphic, non-motile, non-sporulating, mesophilic and can survive both in the host and in the soil [25, 31-35]. Its strains are classified into two biovars, ovis and equi, according to its host preference and nitrate reduction capacity, which is identified through the presence or absence of the narG gene in a PCR Multiplex test [36]. The biovar equi can reduce nitrate and affects mostly large ruminants. The biovar ovis is not able to reduce nitrate and affects mostly small ruminants [4]. More information about classification, general features of this species and some details about the target strains are shown in Table 1 (Additional file 1).

Six C. pseudotuberculosis strains were isolated in Mexico from different hosts and biovars. The strain MEX1 was isolated from a retropharyngeal abscess in a goat. The strain MEX9 was isolated from a prescapular abscess in a goat. The strain MEX25 was isolated from a parotidean abscess in a sheep. The strain MEX29 was isolated from a retropharyngeal abscess in a sheep. These four strains presented negative result for the presence of the narG gene in the PCR multiplex test and were classified as belonging to the biovar ovis. All ovis strains were obtained from outbreaks occurred relatively close to Mexico City. MEX30 and MEX31 were isolated from abscesses in the pectoral muscles of two horses [19]. These two strains were positive for the presence of the narG gene in PCR Multiplex. Consequently, they were classified as belonging to the biovar equi. Although both equi strains were obtained in the same city, they could be considered as isolated cases.

To verify the phylogenetic relationship of these strains to other strains of $C$. pseudotuberculosis, we generated a phylogenetic tree (Fig. 1) based on the core proteome and progressive refinement, using a bootstrap value of 100 . The tree was generated using the PEPR software (https://github.com/enordber/pepr.git) with the Maximum-Likelihood method. The Mexican strains were clustered according to the respective biovars and host preferences, as shown in previous works) [1, 37].
MEX30 and MEX31 were isolated in Valparaiso, in the first reported case of infection of horses in Mexico [19]. They clustered together probably because they came from the same source, that could be transported infected animals. Affected horses were identified in all regions of the US and the state of Texas, which borders Mexico, has the highest number of cases) $[9,21]$.

Ovis strains were isolated in Tlaxcala (MEX1) and Rio Frio de Juárez (MEX29), with a $50 \mathrm{Km}$ distance from each other, and Guanajuato (MEX9 and MEX25), within a 400-450 Km distance from the two other isolation localities. However, the strains cluster by host rather than locality of isolation. MEX1 and MEX9 were isolated from goat and MEX25 and MEX29 were isolated from sheep. However, MEX25 and MEX29 (goat) clustered with isolates from lhama (USA) and cow (Israel), while MEX1 and MEX9 (sheep) clustered with isolates from goat and sheep (Brazil), all with a $100 \%$ bootstrap. Strains of Ovis biovar are more clonal but does not show the same degree of clustering by the host as Equi $[1,37]$. Considering a maximum distance of $450 \mathrm{Km}$ between localities of isolation, this genetic structure could better be explained by farming history than host preference. The goat and sheep farms could have different sources of Ovis strains. Transportation of infected animals and further contact and transmission of the disease probably occurred between farms of the same host species [38-40].

\section{Genome sequencing information} Genome project history

The present project is a collaboration between the National Autonomous University of Mexico (UNAM), Mexico City, Mexico, and the Federal University of Minas Gerais (UFMG), Belo Horizonte, Minas Gerais, Brazil. The six C. pseudotuberculosis strains were isolated by UNAM researchers. Sequencing was performed at the National Reference Laboratory for Aquatic Animal Diseases (AQUACEN), and the two processes of assembly and annotation were performed at the Laboratory of Cellular and Molecular Genetics (LGCM), both laboratories located at UFMG. All genomes are complete and available at the National Center for Biotechnology Information (NCBI). This information is shown in Table 2 and conforms with MIGS recommendations [41]. As mentioned above, the present study presents the first sequencing of C. pseudotuberculosis, and the first isolation of the biovar equi, from Mexico. This data can provide new insights into the diagnosis and treatment of diseases caused by this organism.

\section{Growth conditions and genomic DNA preparation}

The samples used in the present study are in the sample collection of LGCM. All six strains were grown in a 
Table 1 Classification and general features of Corynebacterium strains MEX1, MEX9, MEX25, MEX29, MEX30, and MEX31 according to the MIGS recommendations [41]

\begin{tabular}{|c|c|c|c|}
\hline MIGS ID & Property & Term & Evidence code $^{a}$ \\
\hline & Classification & Domain Bacteria & TAS [23] \\
\hline & & Phylum Actinobacteria & TAS [24] \\
\hline & & Class Actinobacteria & TAS [25] \\
\hline & & Order Actinomycetales Suborder Corynebacterineae & TAS [25-28] \\
\hline & & Family Corynebacteriaceae & $\operatorname{TAS}[25,28]$ \\
\hline & & Genus Corynebacterium & $\operatorname{TAS}[29,30]$ \\
\hline & & Species Corynebacterium pseudotuberculosis & $\operatorname{TAS}[26,29]$ \\
\hline & & $\begin{array}{l}\text { strain: MEX1 (Accession NZ_CP017711.1) } \\
\text { MEX9 (Accession NZ_CP014543.1), } \\
\text { MEX25 (Accession NZ_CP013697.1), } \\
\text { MEX29 (Accession NZ_CP016826.1), } \\
\text { MEX30 (Accession NZ_CP017291.1), } \\
\text { MEX31 (Accession NZ_CP017292.1) }\end{array}$ & \\
\hline & Gram stain & Positive & TAS [31] \\
\hline & Cell shape & Pleomorphic & TAS [31] \\
\hline & Motility & Non-motile & $\operatorname{TAS}[31,35]$ \\
\hline & Sporulation & non-sporulating & TAS [31] \\
\hline & Temperature range & Mesophilic & $\operatorname{TAS}[32,35]$ \\
\hline & Optimum temperature & $37^{\circ} \mathrm{C}$ & TAS $[32,73]$ \\
\hline & pH range; Optimum & $7.0-7.2$ & $\operatorname{TAS}[4,35]$ \\
\hline & Carbon source & Glucose, fructose, maltose, mannose, and sucrose & $\operatorname{TAS}[11,15]$ \\
\hline MIGS-6 & Habitat & Host and soil & $\operatorname{TAS}[25,33,34]$ \\
\hline MIGS-6.3 & Salinity & Up to $2 \mathrm{M} \mathrm{NaCl}$ & TAS [32] \\
\hline MIGS-22 & Oxygen requirement & Aerobic and facultative anaerobic & $\operatorname{TAS}[4,35,73]$ \\
\hline MIGS-15 & Biotic relationship & Facultative intracellular pathogen & $\operatorname{TAS}[4,31]$ \\
\hline MIGS-14 & Pathogenicity & Sheep, goats, horses, cattle, camel, buffalo, rarely humans & $\operatorname{TAS}[4,37,74]$ \\
\hline MIGS-4 & Geographic location & $\begin{array}{l}\text { MEX1 - Ixtenco, Tlaxcala, Mexico } \\
\text { MEX9 - Salamanca, Guanajuato, Mexico } \\
\text { MEX25 - Celaya, Guanajuato, Mexico } \\
\text { MEX29 - Río Frio, Estado de Mexico, Mexico } \\
\text { MEX30 and MEX31 - Valparaiso, Zacatecas, Mexico }\end{array}$ & TAS [19] \\
\hline MIGS-5 & Sample collection & $\begin{array}{l}\text { MEX1-2014, MEX9 and MEX25-2012, } \\
\text { MEX29, MEX30 and MEX31-2013 }\end{array}$ & TAS [19] \\
\hline MIGS-4.1 & Latitude & 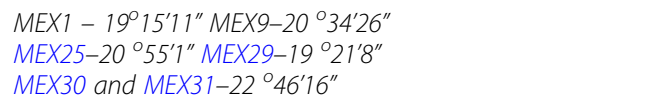 & IDA \\
\hline MIGS-4.2 & Longitude & 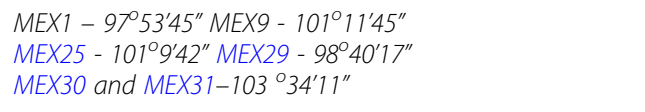 & IDA \\
\hline MIGS-4.4 & Altitude & $\begin{array}{l}\text { MEX1-8236 ft MEX9-5623 ft } \\
\text { MEX25-6502 ft MEX29-9770 ft } \\
\text { MEX30 and MEX31-6221 ft }\end{array}$ & IDA \\
\hline
\end{tabular}

${ }^{\mathrm{a} E v i d e n c e ~ c o d e s ~-~ I D A: ~ I n f e r r e d ~ f r o m ~ D i r e c t ~ A s s a y ; ~ T A S: ~ T r a c e a b l e ~ A u t h o r ~ S t a t e m e n t ~(i . e ., ~ a ~ d i r e c t ~ r e p o r t ~ e x i s t s ~ i n ~ t h e ~ l i t e r a t u r e) ; ~ N A S: ~ N o n-t r a c e a b l e ~ A u t h o r ~ S t a t e m e n t ~}$ (i.e., not directly observed for the living, isolated sample, but based on a generally accepted property for the species, or anecdotal evidence). These evidence codes are from the Gene Ontology project [75]

brain-heart-infusion media (BHI-HiMedia Laboratories Pvt. Ltd., India) with $1.5 \%$ of bacteriological agar and supplemented with $0.5 \%$ of Tween 80 , at $37{ }^{\circ} \mathrm{C}$ for $72 \mathrm{~h}$ under rotation. Genomic DNA was extracted following the protocol of Pacheco et al. [36].

\section{Genome sequencing and assembly}

The first step in sequencing each genome was the library construction, following manufacturer's recommendations (IonXpress ${ }^{\mathrm{TM}}$ Plus gDNA Fragment Library Preparation). This was performed in three steps: (i) DNA 


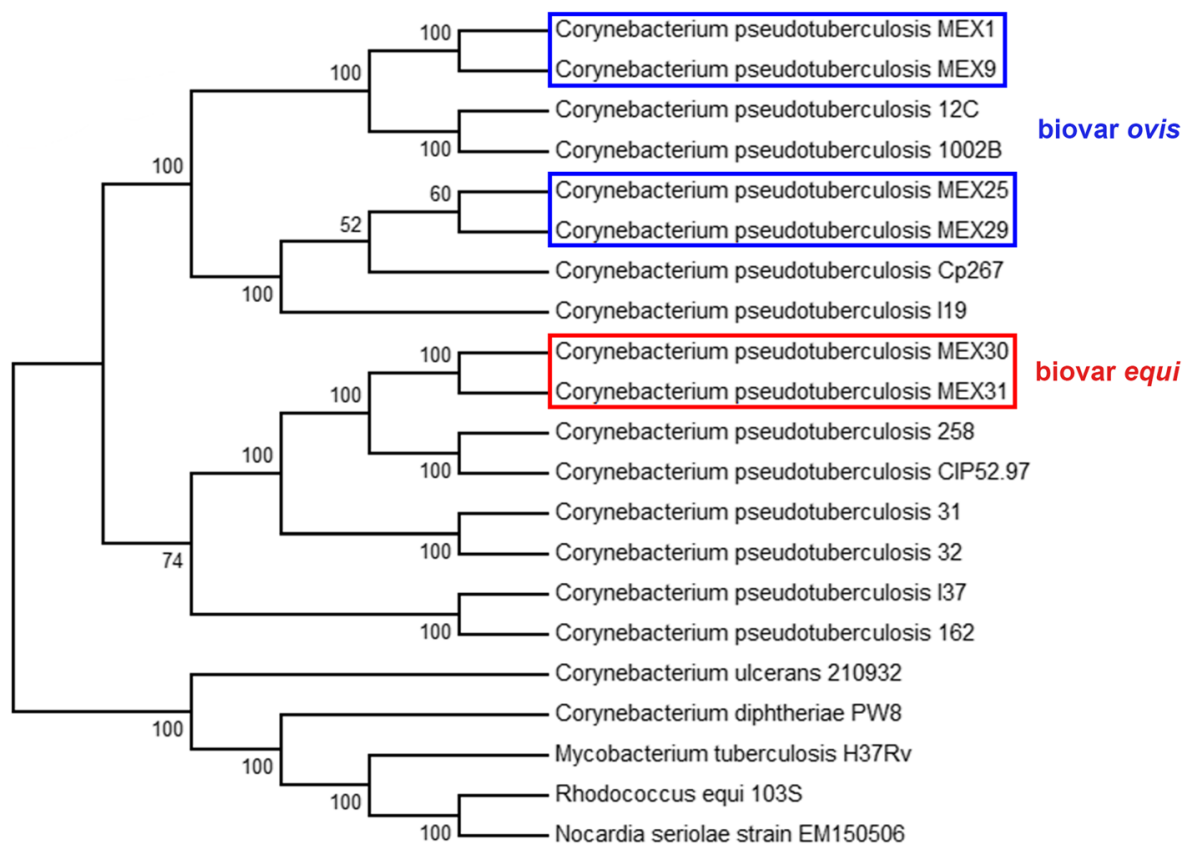

Fig. 1 Phylogenetic tree of new Corynebacterium pseudotuberculosis strains of this work inside the rectangles, with other strains of the group CMNR. The blue rectangles highlight the biovar ovis strains and the red rectangle highlights the biovar equi strains of this work. The numbers near the nodes indicate bootstrap values

fragmentation using the Ion Shear ${ }^{\text {Tx }}$ Plus Reagents Kit, (ii) addition of adapters using Ion Xpress ${ }^{\mathrm{Tm}}$ Barcode Adapters and (iii) library amplification using the Ion PGM ${ }^{\mathrm{Tw}}$ Template OT2 200 kit (all kits from Thermo Fisher Scientific, USA). The resulting library was put on the semiconductor chip Ion 318 Chip Kit v2 (Thermo Fisher Scientific) and then into the sequencer Ion Personal Genome Machine ${ }^{\mathrm{mx}}$ (Thermo Fisher Scientific). The number of reads and the mean read length of MEX1, MEX9, MEX25, MEX29, MEX30 and MEX31 strains are respectively: 1,100,551 and $244 ; 1,496,261$ and $201 ; 1,117,243$ and 206; $1,371,907$ and $230 ; 1,127,325$ and 186; and, 1,262,316 and 230 .

Table 2 Project information

\begin{tabular}{|c|c|c|}
\hline MIGS ID & Property & Term \\
\hline MIGS 31 & Finishing quality & Finished \\
\hline MIGS-28 & Libraries used & Fragments \\
\hline MIGS 29 & Sequencing platforms & Ion Torrent PGM \\
\hline MIGS 31.2 & Fold coverage & 115× (MEX1); 129× (MEX9); 99× (MEX25); 135× (MEX29); 81× (MEX30); 123× (MEX31). \\
\hline MIGS 30 & Assemblers & Newbler, SPAdes. \\
\hline \multirow[t]{6}{*}{ MIGS 32} & Gene calling method & RAST \\
\hline & Locus Tag & $\begin{array}{l}\text { CPMEX1_(MEX1); CpMEX9_(MEX9); AN397_(MEX25); CpMEX29_(MEX29); } \\
\text { CpMEX30_(MEX30); CpMEX31_(MEX31); }\end{array}$ \\
\hline & Genbank ID & $\begin{array}{l}\text { CP017711 (MEX1); CP014543(MEX9); CP013697 (MEX25); CP016826 (MEX29); } \\
\text { CP017291 (MEX30); CP017292 (MEX31); }\end{array}$ \\
\hline & GenBank Date of Release & $\begin{array}{l}\text { 2017/01/30 (MEX1); 2016/05/27 (MEX9); 2015/12/23 (MEX25); 2016/11/03 (MEX29); } \\
\text { 2016/12/27 (MEX30); 2016/12/27 (MEX1); }\end{array}$ \\
\hline & GOLD ID & $\begin{array}{l}\text { - (MEX1); Go0366057 (MEX9); Go0139540 (MEX25); Go0364114 (MEX29); Go0364489 } \\
\text { (MEX30); Go0364678 (MEX31); }\end{array}$ \\
\hline & BIOPROJECT & $\begin{array}{l}\text { PRJNA348354 (MEX1); PRJNA312392 (MEX9); PRJNA294672 (MEX25); PRJNA335634 } \\
\text { (MEX29); PRJNA343017 (MEX30); PRJNA341961 (MEX31); }\end{array}$ \\
\hline \multirow[t]{2}{*}{ MIGS 13} & Source Material Identifier & BHI broth \\
\hline & Project relevance & Animal Pathogen, Medical \\
\hline
\end{tabular}


The assembly process was managed using SIMBA software [42]. The quality assessment of the reads was performed using FastQC software [43]. The assemblies were performed using SPAdes version 3.6 [44] on MEX1 and MEX31; and, Newbler version 2.9 (Roche, USA) on MEX9, MEX25, MEX29, and MEX30. This produced the following contigs: 6 on MEX1, 7 on MEX9, 7 on MEX25, 9 on MEX29, 33 on MEX30 and 13 on MEX31. The N50 s were: 543,202 on MEX1, 372,309 on MEX9, 543,326 on MEX25, 367,275 on MEX29, 103,276 on MEX30 and 535,978 on MEX31. The QUAST software [45] was used to evaluate the quality of the assemblies for all strains. The scaffolds were constructed using CONTIGuator software version 2.0 [46] with C. pseudotuberculosis strain 29,156 (CP010795.1) as a reference to MEX9, MEX25 and MEX29, C. pseudotuberculosis strain MEX9 as a reference to MEX1, C. pseudotuberculosis strain 316 (CP003077.1) as a reference to MEX30 and $C$. pseudotuberculosis strain E19 (CP012136.1) as a reference to MEX31. Gap closure was performed using CLC Genomics Workbench 7 (Qiagen, USA). This process resulted in six complete genome sequences.

\section{Genome annotation}

Genome annotation was performed in two steps: automatic annotation and manual curation. The RAST [47] and tRNAscan-SE [48] software were used in the automated annotation. An in-house script was also employed to transfer the annotation from a reference genome. The Artemis software version 16.0.0 [49], the UniProt [50] and the National Center for Biotechnology Information (NCBI) databases [51] were used in the manual curation.
Putative frameshifts were analyzed using CLC Genomics Workbench 7 (Qiagen, USA) and fixed whenever possible.

\section{Genome properties}

Genome sizes of the respective strains are: 2,337,090 bp (base pairs) on MEX1, 2,337,578 bp on MEX9, 2,337,529 bp on MEX25, 2,337,866 bp on MEX29, 2,368,140 bp on MEX30 and 2,367,880 bp on MEX31. The respective percentages of the predicted coding regions are: $86.16 \%$ on MEX1, $86.33 \%$ on MEX9, $85.94 \%$ on MEX25, $86.66 \%$ on MEX29, $83.06 \%$ on MEX30 and $86.64 \%$ on MEX31. These genome sizes and the $\mathrm{G}+\mathrm{C}$ content $(\sim 52 \%)$ are consistent with other C. pseudotuberculosis studies $[2,6,52]$. There are 64 predicted RNA genes in strains of the biovar ovis (MEX1, MEX9, MEX25 and MEX29) and 66 from the biovar equi (MEX30 and MEX31). The numbers (and percentages) of predicted protein coding genes and pseudogenes of MEX1, MEX9, MEX25, MEX29, MEX30 and MEX31 strains are, respectively: 2021 (94.22\%) and 60 (2.80\%); 2025 (94.36\%) and 57 (2.66\%); 2016 (94.07\%) and 63 (2.94\%); 2032 (94.73\%) and 49 (2.28\%); $2008(91.77 \%)$ and 114 (5.21\%); and 2058 (94.32\%) and 61 (2.80\%). Table 3 shows detailed information about properties and statistics of these genomes. The number of genes associated with general COG functional categories [53, 54] was generated with the in-house script Blast Cog (https:/github.com/aquacen/blast_cog) and are summarized in Table 4. The circular maps of C. pseudotuberculosis MEX1 and MEX30 strains in comparison with the other strains of the present study are shown in Figs. 2 and 3 , respectively.

Table 3 Genome statistics

\begin{tabular}{|c|c|c|c|c|c|c|c|c|c|c|c|c|}
\hline \multirow[t]{2}{*}{ Attribute } & \multicolumn{2}{|l|}{ MEX1 } & \multicolumn{2}{|l|}{ MEX9 } & \multicolumn{2}{|l|}{ MEX25 } & \multicolumn{2}{|l|}{ MEX29 } & \multicolumn{2}{|l|}{ MEX30 } & \multicolumn{2}{|l|}{ MEX31 } \\
\hline & Value & $\%$ & Value & $\%$ & Value & $\%$ & Value & $\%$ & Value & $\%$ & Value & $\%$ \\
\hline Genome size (bp) & $2,337,090$ & 100.0 & $2,337,578$ & 100.0 & $2,337,529$ & 100.0 & $2,337,866$ & 100.0 & $2,368,140$ & 100.0 & $2,367,880$ & 100.0 \\
\hline DNA coding (bp) & $2,012,758$ & 86.12 & $2,017,915$ & 86.33 & 2008,915 & 85.94 & 2025,972 & 86.66 & $1,966,942$ & 83.06 & $2,051,473$ & 86.64 \\
\hline DNA G + C (bp) & $1,219,520$ & 52.18 & $1,219,842$ & 52.18 & $1,219,763$ & 52.18 & $1,219,957$ & 52.18 & $1,234,064$ & 52.11 & $1,233,547$ & 52.10 \\
\hline DNA scaffolds & 1 & 100.0 & 1 & 100.0 & 1 & 100.0 & 1 & 100.0 & 1 & 100.0 & 1 & 100.0 \\
\hline Total genes & 2145 & 100.0 & 2146 & 100.0 & 2143 & 100.0 & 2145 & 100.0 & 2188 & 100.0 & 2182 & 100.0 \\
\hline Protein coding genes & 2021 & 94.22 & 2025 & 94.36 & 2016 & 94.07 & 2032 & 94.73 & 2008 & 91.77 & 2058 & 94.32 \\
\hline RNA genes & 64 & 2.98 & 64 & 2.98 & 64 & 2.99 & 64 & 2.98 & 66 & 3.02 & 63 & 2.89 \\
\hline Pseudo genes & 60 & 2.80 & 57 & 2.66 & 63 & 2.94 & 49 & 2.28 & 114 & 5.21 & 61 & 2.80 \\
\hline Genes in internal clusters & NA & NA & NA & NA & NA & NA & NA & NA & NA & NA & NA & NA \\
\hline Genes with function prediction & 1579 & 73.61 & 1576 & 73.44 & 1583 & 73.87 & 1578 & 73.57 & 1605 & 73.36 & 1610 & 73.79 \\
\hline Genes assigned to COGs & 2007 & 93.57 & 2013 & 93.80 & 2009 & 93.75 & 2020 & 94.17 & 1998 & 91.32 & 2046 & 93.77 \\
\hline Genes with Pfam domains & 1679 & 78.28 & 1675 & 78.05 & 1670 & 77.93 & 1690 & 78.79 & 1664 & 76.05 & 1731 & 79.33 \\
\hline Genes with signal peptides & 157 & 7.32 & 151 & 7.04 & 159 & 7.42 & 155 & 7.23 & 144 & 6.58 & 153 & 7.01 \\
\hline Genes with transmembrane helices & 595 & 27.74 & 591 & 27.54 & 585 & 27.30 & 601 & 28.02 & 585 & 26.74 & 596 & 27.31 \\
\hline CRISPR repeats & 0 & 000 & 1 & 0.05 & 1 & 0.05 & 1 & 0.05 & 4 & 0.18 & 4 & 0.18 \\
\hline
\end{tabular}


Table 4 Number of genes associated with general COG functional categories

\begin{tabular}{|c|c|c|c|c|c|c|c|c|c|c|c|c|c|}
\hline \multirow[t]{2}{*}{ Code } & \multicolumn{2}{|l|}{ MEX1 } & \multicolumn{2}{|l|}{ MEX9 } & \multicolumn{2}{|c|}{ MEX25 } & \multicolumn{2}{|c|}{ MEX29 } & \multicolumn{2}{|c|}{ MEX30 } & \multicolumn{2}{|c|}{ MEX31 } & \multirow[t]{2}{*}{ Description } \\
\hline & Value & \%age & Value & \%age & Value & \%age & Value & \%age & Value & \%age & Value & \%age & \\
\hline J & 182 & 9.01 & 182 & 8.99 & 181 & 8.98 & 186 & 9.15 & 183 & 9.11 & 189 & 9.18 & Translation, ribosomal structure and biogenesis \\
\hline A & 2 & 0.10 & 2 & 0.10 & 2 & 0.10 & 2 & 0.10 & 2 & 0.10 & 2 & 0.10 & RNA processing and modification \\
\hline K & 138 & 6.83 & 139 & 6.87 & 137 & 6.80 & 138 & 6.79 & 136 & 6.77 & 134 & 6.51 & Transcription \\
\hline L & 105 & 5.20 & 105 & 5.19 & 96 & 4.76 & 102 & 5.02 & 102 & 5.08 & 101 & 4.91 & Replication, recombination and repair \\
\hline B & 0 & 0 & 0 & 0 & 0 & 0 & 0 & 0 & 1 & 0.05 & 0 & 0 & Chromatin structure and dynamics \\
\hline D & 44 & 2.18 & 43 & 2.12 & 45 & 2.23 & 45 & 2.22 & 43 & 2.14 & 47 & 2.28 & $\begin{array}{l}\text { Cell cycle control, Cell division, chromosome } \\
\text { partitioning }\end{array}$ \\
\hline V & 68 & 3.37 & 67 & 3.31 & 69 & 3.42 & 71 & 3.49 & 75 & 3.74 & 70 & 3.40 & Defense mechanisms \\
\hline $\mathrm{T}$ & 99 & 4.90 & 101 & 4.99 & 99 & 4.91 & 103 & 5.07 & 98 & 4.88 & 98 & 4.76 & Signal transduction mechanisms \\
\hline M & 124 & 6.14 & 122 & 6.03 & 119 & 5.90 & 120 & 5.91 & 119 & 5.93 & 117 & 5.69 & Cell wall/membrane biogenesis \\
\hline N & 21 & 1.04 & 22 & 1.09 & 20 & 0.99 & 20 & 0.98 & 13 & 0.65 & 17 & 0.83 & Cell motility \\
\hline U & 32 & 1.58 & 31 & 1.53 & 30 & 1.49 & 31 & 1.53 & 29 & 1.44 & 30 & 1.46 & Intracellular trafficking and secretion \\
\hline O & 128 & 6.33 & 122 & 6.03 & 121 & 6.00 & 126 & 6.20 & 122 & 6.08 & 122 & 5.93 & $\begin{array}{l}\text { Posttranslational modification, protein turnover, } \\
\text { chaperones }\end{array}$ \\
\hline C & 125 & 6.19 & 124 & 6.12 & 116 & 5.75 & 124 & 6.10 & 123 & 6.13 & 121 & 5.88 & Energy production and conversion \\
\hline G & 158 & 7.82 & 154 & 7.61 & 151 & 7.49 & 156 & 7.68 & 151 & 7.52 & 161 & 7.82 & Carbohydrate transport and metabolism \\
\hline E & 212 & 10.49 & 213 & 10.52 & 204 & 10.12 & 213 & 10.48 & 219 & 10.91 & 223 & 10.84 & Amino acid transport and metabolism \\
\hline $\mathrm{F}$ & 82 & 4.06 & 82 & 4.05 & 79 & 3.92 & 82 & 4.04 & 78 & 3.88 & 81 & 3.94 & Nucleotide transport and metabolism \\
\hline $\mathrm{H}$ & 143 & 7.08 & 141 & 6.96 & 135 & 6.70 & 141 & 6.94 & 151 & 7.52 & 152 & 7.39 & Coenzyme transport and metabolism \\
\hline । & 92 & 4.55 & 91 & 4.49 & 90 & 4.46 & 93 & 4.58 & 86 & 4.28 & 87 & 4.23 & Lipid transport and metabolism \\
\hline$P$ & 162 & 8.02 & 157 & 7.75 & 162 & 8.04 & 162 & 7.97 & 166 & 8.27 & 168 & 8.16 & Inorganic ion transport and metabolism \\
\hline Q & 49 & 2.43 & 46 & 2.27 & 46 & 2.28 & 48 & 2.36 & 52 & 2.59 & 50 & 2.43 & $\begin{array}{l}\text { Secondary metabolites biosynthesis, transport, } \\
\text { and catabolism }\end{array}$ \\
\hline R & 170 & 8.41 & 164 & 8.10 & 157 & 7.79 & 167 & 8.22 & 167 & 8.32 & 169 & 8.21 & General function prediction only \\
\hline S & 138 & 6.83 & 142 & 7.01 & 127 & 6.30 & 141 & 6.94 & 138 & 6.87 & 140 & 6.80 & Function unknown \\
\hline- & 14 & 0.69 & 12 & 0.59 & 7 & 0.35 & 12 & 0.59 & 10 & 0.50 & 12 & 0.58 & Not in COGs \\
\hline
\end{tabular}

The total is based on the total number of protein coding genes in the genome

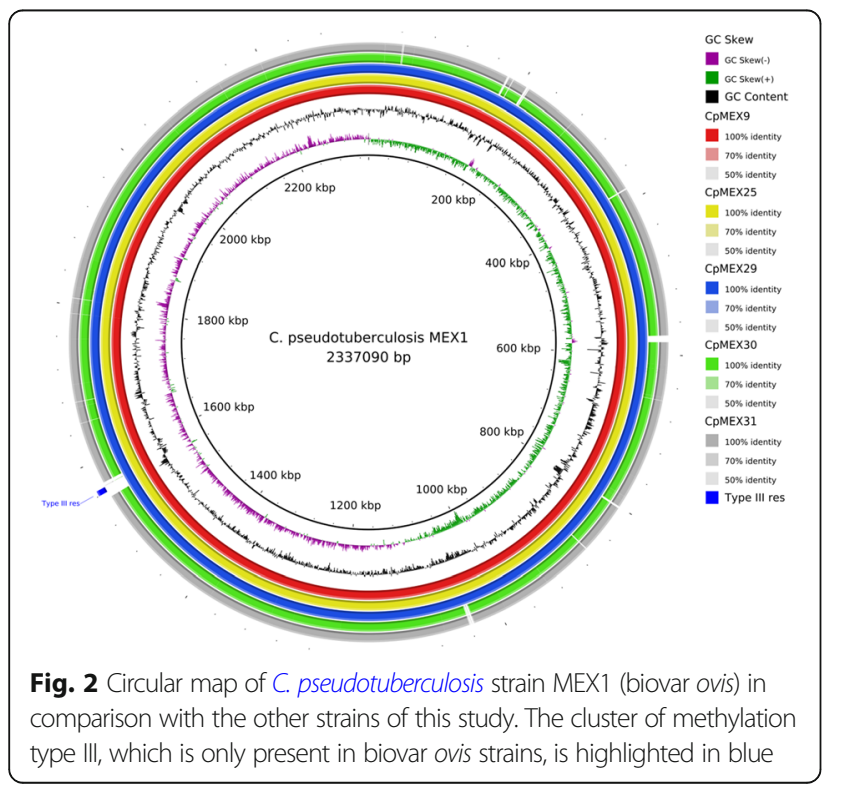

\section{Insights from the genome sequence}

The nucleotide sequences, analyzed using the Gegenees software version 2.1 [55], show high similarity $(>92 \%)$ between the strains. Higher similarity $(>=99.7 \%)$ within strains belonging to the same biovar was found (Fig. 4). This is consistent with a previous study [1], using 15 strains of C. pseudotuberculosis, that shows similarity greater than $99 \%$ within the biovar ovis strains and at least $95 \%$ of sequencing similarity within the biovar equi strains. Moreover, the sequencing similarity among strains isolated from the same host is higher than the similarity among strains isolated from different hosts (Figs. 1 and 4).

Traditionally, the two biovars are differentiated using a nitrate reduction test, in which equi is positive, and ovis is negative [56]. Figure 3 highlights the cluster of genes related to nitrate reduction in Mexican equi strains with the black rectangle. The Protein Family Sorter tool [57] was used to search for genes or clusters of genes that may be used to differentiate the biovars. Within the six 


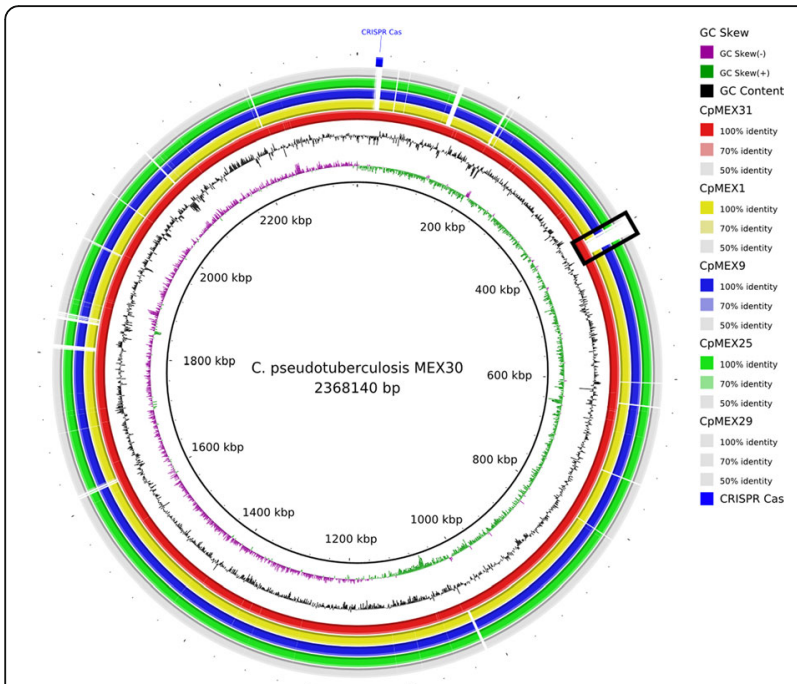

Fig. 3 Circular map of C. pseudotuberculosis strain MEX30 (biovar equi) in comparison with the other strains of this study. The cluster of CRISPRCas, which is only present in biovar equi strains, is highlighted in blue. The nitrate reductase gene cluster is highlighted by a black rectangle

genomes of the present study, we found the cluster of genes that is related to proteins of type III restrictionmodification (RM) systems $[58,59]$ exclusively in the biovar ovis (highlighted in blue in Fig. 2). A cluster of genes related to the proteins of Clustered Regularly Interspaced Short Palindromic Repeats (CRISPR-Cas) systems, probably belonging to type I-E [60], was found exclusively in the biovar equi (highlighted in blue in Fig. 3). Both systems work as protection systems, defending the bacteria against exogenous DNA. We analyzed 40 other sequenced strains of C. pseudotuberculosis to confirm these results in other strains. The same pattern was observed.

RM systems have two main components, a DNA methyltransferase, and a restriction endonuclease. The first one methylates the DNA in possible cleavage sites; the second one is responsible for the cleavage of DNA from external sources [61]. A good review of RM systems can be found in [62]. CRISPR-Cas systems are adaptive immune systems in bacteria and archaea. They use a complex of proteins known as Cas that are responsible for acquiring new, short sequences of external sources (exogenous genetic elements). These short sequences are incorporated into the bacterial chromosome and are called CRISPRs. The CRISPRs are transcribed into small RNAs that guide the Cas proteins to recognize and cleave foreign DNA, protecting the bacterial genome [63]. Reviews of CRISPR-Cas systems can be found in [63-65].

Possible new drug targets were predicted using the Specialty Genes Search from the Pathosystems Resource Integration Center (PATRIC) bioinformatics resource center [66]. The result shows a new putative target, the gene $n r d F 2$, for five of the six strains used in the present study. In the C. pseudotuberculosis MEX30 strain, this gene is annotated as a pseudogene, which can explain why it was not considered a putative target. The product of this gene is the small subunit of ribonucleotide reductase (RNR) which is involved in dNTP (deoxynucleotide triphosphate) synthesis that reduces ribonucleotides to nucleotides. The RNRs can be classified into three classes (I, II and III). Class I is oxygen dependent and has two subclasses (Ia and Ib). Class Ia is coded by $n r d A$ and $n r d B$ genes; class Ib is coded by $n r d E$ and $n r d F$. Therefore, the RNR found in the biovar ovis strains belongs to class Ib [67]. Previous studies [68-70] show the importance of this gene for growth under normal conditions (in vitro) in Mycobacterium tuberculosis, Corynebacterium ammoniagenes and Corynebacterium glutamicum. Additionally, other studies have pointed to this gene as a potential target of $M$. tuberculosis vaccine [70-72].

\section{Conclusions}

In the present study, we investigated six strains of $C$. pseudotuberculosis from different hosts and their sequenced genomes, the first whole-genome investigation of this organism from Mexico. The phylogenomic

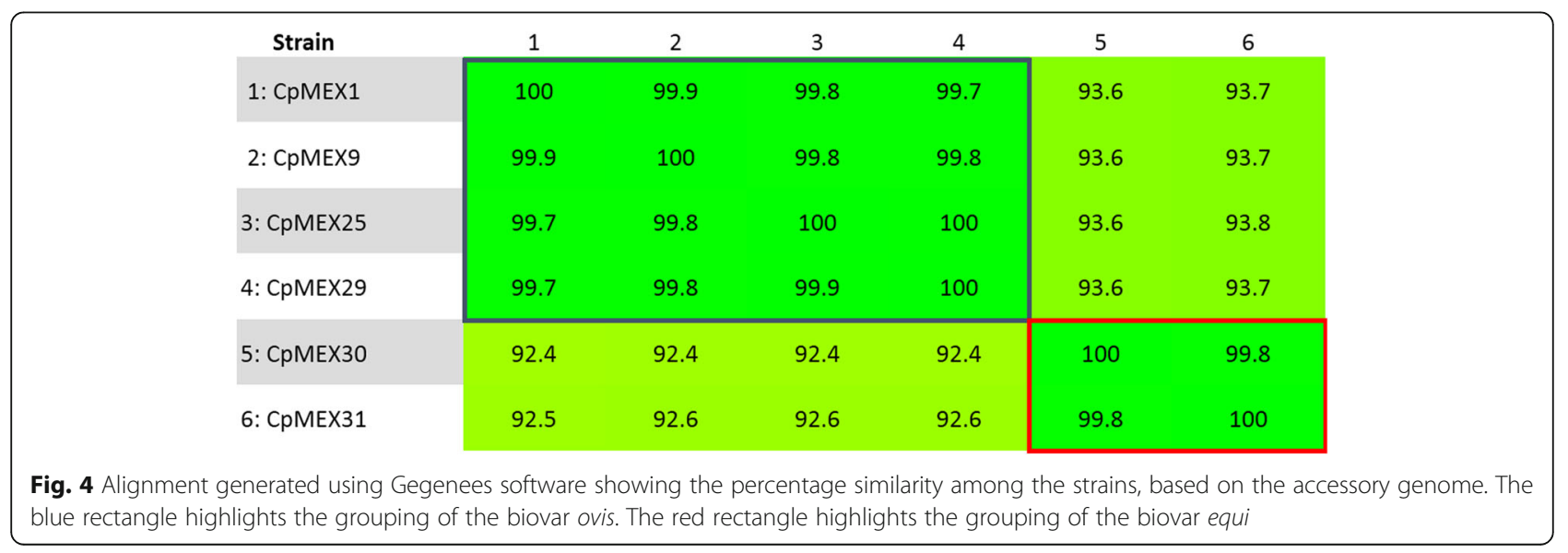


analysis suggested that the genetic structure of Ovis is more influenced by animal transportation than host preference. An in silico analysis of protein families showed two important clusters that may differentiate the biovars equi and ovis. Also, the present work identified a new putative drug target against C. pseudotuberculosis, the gene $n r d F 2$, which has been previously described as a potential vaccine target [70-72]. Further in silico and in vitro analyses are required to validate these findings. Those results could provide a better understanding of this organism and its mechanisms of virulence and pathogenesis, as well as develop new diagnoses, vaccines, and treatments.

\section{Additional file}

Additional file 1: Contains tables Annotation Summary, GenBank Accession Summary, Strain ID Summary, Plant Name Summary, Scientific Name Summary and Reference Search Summary. (DOCX 17 kb)

\section{Abbreviations}

AQUACEN: National Reference Laboratory for Aquatic Animal Diseases; BHI: Brain heart infusion; CRISPR: Clustered regularly interspaced short palindromic repeats; LGMC: Laboratory of Cellular and Molecular Genetics; PATRIC: Pathosystems Resource Integration Center; PEPR: Phylogenomic Estimation with Progressive Refinement; RM systems: Restriction-modification; UFMG: Federal University of Minas Gerais; UNAM: National Autonomous University of Mexico

\section{Acknowledgements}

The authors thank the Brazilian funding agencies, CNPq, CAPES, and FAPEMIG for providing financial support to the National Institute of Science and Technology in Theranostics and Nanobiotechnology - INCT-TeraNano (CNPq/CAPES/FAPEMIG, Grant numbers CNPq-465669/2014-0 and FAPEMIGCBB-APQ-03613-17). Debmalya Barh acknowledges the "TWAS-CNPq Postdoctoral Fellowship Programme" for granting a fellowship for postdoctoral studies.

\section{Authors' contributions}

DP and MTDP wrote the paper. DP, MTDP, and MVCV performed assembly, annotation and in silico analyses. AVMB, ACP, BAR, and EDA isolated the samples. FAD, FLP, AFC and HCPF sequenced the samples. PG, DB, ACPG, and VACA worked on conception, design, coordination of this study and helped to write the paper. All authors read and approved the final manuscript.

\section{Competing interests}

The authors declare that they have no competing interests.

\section{Publisher's Note}

Springer Nature remains neutral with regard to jurisdictional claims in published maps and institutional affiliations.

\section{Author details}

'Laboratory of Cellular and Molecular Genetics, Institute of Biologic Sciences, Federal University of Minas Gerais, Belo Horizonte, MG, Brazil. ${ }^{2}$ Department of Microbiology and Immunology, Faculty of Veterinary Medicine and Zootechnics, National Autonomous University of Mexico, Mexico City, Mexico. ${ }^{3}$ Aquacen - National Reference Laboratory for Aquatic Animal Diseases, Federal University of Minas Gerais, Belo Horizonte, MG, Brazil. ${ }^{4}$ Department of Computer Science, Virginia Commonwealth University, Richmond VA-23284, USA. ${ }^{5}$ Centre for Genomics and Applied Gene Technology, Institute of Integrative Omics and Applied Biotechnology (IIOAB), Nonakuri, Purba Medinipur, West Bengal 721172, India. ${ }^{6}$ Division of Bioinformatics and Computational Genomics, NITTE University Center for Science Education and Research (NUCSER), NITTE (Deemed to be University), Deralakatte, Mangaluru, Karnataka, India.
Received: 25 July 2017 Accepted: 24 September 2018

Published online: 10 October 2018

\section{References}

1. Soares SC, Silva A, Trost E, Blom J, Ramos R, Carneiro A, Ali A, et al. The pangenome of the animal pathogen Corynebacterium pseudotuberculosis reveals differences in genome plasticity between the biovar ovis and equi strains. PLoS One. 2013;8(1):e53818.

2. Baraúna RA, Ramos RT, Veras $A A$, de Sá PH, Guimarães $L C$, das Graças $D A$, et al. Genomic analysis of four strains of Corynebacterium pseudotuberculosis bv. Equi isolated from horses showing distinct signs of infection. Stand Genomic Sci. 2017;12(1):16.

3. Barba M, Stewart AJ, Passler T, Wooldridge AA, Santen E, Chamorro MF, et al. Experimental transmission of Corynebacterium pseudotuberculosis biovar equi in horses by house flies. J Vet Intern Med. 2015;29(2):636-43.

4. Dorella FA, Pacheco LG, Oliveira SC, Miyoshi A, Azevedo V. Corynebacterium pseudotuberculosis: microbiology, biochemical properties, pathogenesis and molecular studies of virulence. Vet Res. 2006;37(2):201-18.

5. Trost E, Ott L, Schneider J, Schröder J, Jaenicke S, Goesmann A, et al. The complete genome sequence of Corynebacterium pseudotuberculosis FRC41 isolated from a 12-year-old girl with necrotizing lymphadenitis reveals insights into gene-regulatory networks contributing to virulence. BMC Genomics. 2010;11(1):728.

6. Almeida S, Tiwari S, Mariano D, Souza F, Jamal SB, Coimbra N, et al. The genome anatomy of Corynebacterium pseudotuberculosis VD57 a highly virulent strain causing Caseous lymphadenitis. Stand Genomic Sci. 2016; 11(1):29.

7. Peel MM, Palmer GG, Stacpoole AM, Kerr TG. Human lymphadenitis due to Corynebacterium pseudotuberculosis: report of ten cases from Australia and review. Clin Infect Dis. 1997;24(2):185-91.

8. House RW, Schousboe M, Allen JP, Grant CC. Corynebacterium ovis (pseudotuberculosis) lymphadenitis in a sheep farmer: a new occupational disease in New Zealand. The New Zealand medical journal. 1986;99(809):659-62.

9. Kilcoyne I, Spier SJ, Carter CN, Smith JL, Swinford AK, Cohen ND. Frequency of Corynebacterium pseudotuberculosis infection in horses across the United States during a 10-year period. J Am Vet Med Assoc. 2014;245(3):309-14.

10. Seyffert N, Guimarães AS, Pacheco LG, Portela RW, Bastos BL, Dorella FA, et al. High seroprevalence of caseous lymphadenitis in Brazilian goat herds revealed by Corynebacterium pseudotuberculosis secreted proteins-based ELISA. Res Vet Sci. 2010;88(1):50-5.

11. Müller B, de Klerk-Lorist LM, Henton MM, Lane E, Parsons S, van Pittius NC, et al. Mixed infections of Corynebacterium pseudotuberculosis and nontuberculous mycobacteria in south African antelopes presenting with tuberculosis-like lesions. Vet Microbiol. 2011;147(3):340-5.

12. Connor KM, Quirie MM, Baird G, Donachie W. Characterization of United Kingdom isolates of Corynebacterium pseudotuberculosis using pulsed-field gel electrophoresis. J Clin Microbiol. 2000;38(7):2633-7.

13. Ben SM, Ben MH, Benzarti M, Messadi L, Rejeb A, Amara A. Epidemiological and clinical studies of ovine caseous lymphadenitis. Arch Inst Pasteur Tunis. 2002;79(1-4):51-7.

14. Arsenault J, Girard C, Dubreuil P, Daignault D, Galarneau JR, Boisclair J, et al. Prevalence of and carcass condemnation from maedi-visna, paratuberculosis and caseous lymphadenitis in culled sheep from Quebec, Canada. Preventive veterinary medicine. 2003;59(1):67-81.

15. Paton MW, Walker SB, Rose IR, Watt GF. Prevalence of caseous lymphadenitis and usage of caseous lymphadenitis vaccines in sheep flocks. Aust Vet J. 2003; 81(1-2):91-5.

16. Selim SA. Oedematous skin disease of buffalo in Egypt. Zoonoses Public Health. 2001:48(4):241-58.

17. Silva A, Schneider MP, Cerdeira L, Barbosa MS, Ramos RT, Carneiro AR, et al. Complete genome sequence of Corynebacterium pseudotuberculosis 119, a strain isolated from a cow in Israel with bovine mastitis. J Bacteriol. 2011; 193(1):323-4.

18. Oliveira M, Barroco C, Mottola C, Santos R, Lemsaddek A, Tavares L, et al. First report of Corynebacterium pseudotuberculosis from caseous lymphadenitis lesions in black Alentejano pig (Sus scrofa domesticus). BMC Vet Res. 2014; 10(1):218.

19. Muñoz-Bucio AV, Cortés-Pérez YA, Arellano-Reynoso B, Hernández-Gil M, Hernández-Castro R, Díaz-Aparicio E. Identification of Corynebacterium pseudotuberculosis isolated from muscular abscesses in two horses: first report in Mexico. Equine Veterinary Education. 2016;29:431-5. 
20. Loureiro D, Portela RW, Sousa TJ, Rocha F, Pereira FL, Dorella FA, et al. Complete genome sequence of Corynebacterium pseudotuberculosis viscerotropic strain N1. Genome announcements. 2016;4(1):e01673-15.

21. Spier SJ, Azevedo V. Corynebacterium pseudotuberculosis infection in horses: increasing frequency and spread to new regions of North America. Equine Veterinary Education. 2016;29:436-9.

22. Tauch A, Sandbote J. The family Corynebacteriaceae. In: The prokaryotes: Springer Berlin Heidelberg; 2014. p. 239:277.

23. Woese CR, Kandler O, Wheelis ML. Towards a natural system of organisms: proposal for the domains archaea, Bacteria, and Eucarya. Proc Natl Acad Sci. 1990;87(12):4576-9.

24. Garrity GM, Holt JG. The road map to the manual. Bergey's Manual of Systematics of Archaea and Bacteria. 2001;1:119-66.

25. Stackebrandt E, Rainey FA, Ward-Rainey NL. Proposal for a new hierarchic classification system, Actinobacteria classis nov. Int J Syst Evol Microbiol. 1997:47(2):479-91

26. Skerman VB, McGowan V, Sneath PH. Approved lists of bacterial names. Int J Syst Evol Microbiol. 1980;30(1):225-420.

27. Buchanan RE. Studies in the nomenclature and classification of the bacteria: II. The primary subdivisions of the schizomycetes. J Bacteriol. 1917;2(2):155.

28. Zhi XY, Li WJ, Stackebrandt E. An update of the structure and 16S rRNA gene sequence-based definition of higher ranks of the class Actinobacteria, with the proposal of two new suborders and four new families and emended descriptions of the existing higher taxa. Int J Syst Evol Microbiol. 2009:59(3):589-608.

29. Lehmann KB, Neumann R. Lehmann's Medizin, Handatlanten. X Atlas und Grundriss der Bakteriologie und Lehrbuch der speziellen bakteriologischen Diagnostik. 1907;2:270.

30. Bernard KA, Wiebe D, Burdz T, Reimer A, Ng B, Singh C, et al. Assignment of Brevibacterium stationis (ZoBell and Upham 1944) breed 1953 to the genus Corynebacterium, as Corynebacterium stationis comb. nov., and emended description of the genus Corynebacterium to include isolates that can alkalinize citrate. Int J Syst Evol Microbiol. 2010;60(4):874-9.

31. Moura-Costa LF, Bahia RC, Carminati R, Vale VL, Paule BJ, Portela RW, et al. Evaluation of the humoral and cellular immune response to different antigens of Corynebacterium pseudotuberculosis in Canindé goats and their potential protection against caseous lymphadenitis. Vet Immunol Immunopathol. 2008;126(1):131-41.

32. Pinto AC, de Sá PH, Ramos RT, Barbosa S, Barbosa HP, Ribeiro AC, et al. Differential transcriptional profile of Corynebacterium pseudotuberculosis in response to abiotic stresses. BMC Genomics. 2014;15(1):14.

33. Aleman M, Spier SJ, Wilson WD, Doherr M. Corynebacterium pseudotuberculosis infection in horses: 538 cases (1982-1993). J Am Vet Med Assoc. 1996;209(4):804-9.

34. Spier SJ, Toth B, Edman J, Quave A, Habasha F, Garrick M, et al. Survival of Corynebacterium pseudotuberculosis biovar equi in soil. Vet Rec. 2012;170:180-1. vetrec-2011.

35. Merchant IA, Packer RA. Veterinary bacteriology and virology. Ames: lowa State University Press; 1967. p. 752.

36. Pacheco LG, Pena RR, Castro TL, Dorella FA, Bahia RC, Carminati R, et al. Multiplex PCR assay for identification of Corynebacterium pseudotuberculosis from pure cultures and for rapid detection of this pathogen in clinical samples. J Med Microbiol. 2007;56(4):480-6.

37. Viana MV, Figueiredo H, Ramos R, Guimarães LC, Pereira FL, Dorella FA, et al. Comparative genomic analysis between Corynebacterium pseudotuberculosis strains isolated from buffalo. PLoS One. 2017;12(4):e0176347.

38. Gebrekidan H, Nelson L, Smith G, Gasser RB, Jabbar A. An outbreak of oriental theileriosis in dairy cattle imported to Vietnam from Australia. Parasitology. 2017;144(6):738-46

39. Keim PS, Wagner DM. Humans and evolutionary and ecological forces shaped the phylogeography of recently emerged diseases. Nat Rev Microbiol. 2009;7(11):813-21.

40. Skuce RA, Mallon TR, McCormick CM, McBride SH, Clarke G, Thompson A, Couzens C, Gordon AW, McDowell SW. Mycobacterium bovis genotypes in Northern Ireland: herd-level surveillance (2003 to 2008). The Veterinary record. 2010;167(18):684-9.

41. Field D, Garrity G, Gray T, Morrison N, Selengut J, Sterk P, et al. The minimum information about a genome sequence (MIGS) specification. Nat Biotechnol. 2008;26(5):541-7.

42. Mariano DC, Pereira FL, Aguiar EL, Oliveira LC, Benevides L, Guimarães LC, et al. SIMBA: a web tool for managing bacterial genome assembly generated by ion PGM sequencing technology. BMC bioinformatics. 2016;17(18):456.
43. Babraham Bioinformatics: FastQC. https://github.com/s-andrews/FastQC. Accessed 14 June 2017.

44. Bankevich A, Nurk S, Antipov D, Gurevich AA, Dvorkin M, Kulikov AS, et al. SPAdes: a new genome assembly algorithm and its applications to singlecell sequencing. J Comput Biol. 2012;19(5):455-77.

45. Gurevich A, Saveliev V, Vyahhi N, Tesler G. QUAST: quality assessment tool for genome assemblies. Bioinformatics. 2013;29(8):1072-5.

46. Galardini M, Biondi EG, Bazzicalupo M, Mengoni A. CONTIGuator: a bacterial genomes finishing tool for structural insights on draft genomes. Source code for biology and medicine. 2011;6(1):11.

47. Aziz RK, Bartels D, Best AA, DeJongh M, Disz T, Edwards RA, et al. The RAST server: rapid annotations using subsystems technology. BMC Genomics. 2008;9(1):75.

48. Lowe TM, Eddy SR. tRNAscan-SE: a program for improved detection of transfer RNA genes in genomic sequence. Nucleic Acids Res. 1997;25(5): 955-64.

49. Rutherford K, Parkhill J, Crook J, Horsnell T, Rice P, Rajandream MA, et al. Artemis: sequence visualization and annotation. Bioinformatics. 2000;16(10): 944-5.

50. Uniprot DB. UniProt Consortium. http://www.uniprot.org/. Accessed 15 June 2017.

51. NCBI. https://www.ncbi.nlm.nih.gov/. Accessed in 15 Jun 2017.

52. Hassan SS, Guimarães LC, Pereira UP, Islam A, Ali A, Bakhtiar SM, et al. Complete genome sequence of Corynebacterium pseudotuberculosis biovar ovis strain P54B96 isolated from antelope in South Africa obtained by rapid next generation sequencing technology. Stand Genomic Sci. 2012;7(2):189.

53. Galperin MY, Makarova KS, Wolf YI, Koonin EV. Expanded microbial genome coverage and improved protein family annotation in the COG database. Nucleic acids res. 2015;43:D261-9.

54. Tatusov RL. A genomic perspective on protein families. Science (80-. ). 1997; 278:631-7.

55. Ågren J, Sundström A, Håfström T, Segerman B. Gegenees: fragmented alignment of multiple genomes for determining phylogenomic distances and genetic signatures unique for specified target groups. PLoS One. 2012;7(6): e39107

56. Biberstein EL, Knight HD, Jang S. Two biotypes of Corynebacterium pseudotuberculosis. Vet Rec. 1971;89:691-2.

57. Davis JJ, Gerdes S, Olsen GJ, Olson R, Pusch GD, Shukla M, et al. PATtyFams: protein families for the microbial genomes in the PATRIC database. Front Microbiol. 2016:7:118.

58. Kwiatek A, Mrozek A, Bacal P, Piekarowicz A, Adamczyk-Popławska M. Type III methyltransferase M. NgoAX from Neisseria gonorrhoeae FA1090 regulates biofilm formation and interactions with human cells. Front Microbiol. 2015; 6:1426.

59. Tan A, Hill DM, Harrison OB, Srikhanta YN, Jennings MP, Maiden MC, et al. Distribution of the type III DNA methyltransferases modA, modB and modD among Neisseria meningitidis genotypes: implications for gene regulation and virulence. Sci Rep. 2016;6:21015.

60. Sangal V, Fineran PC, Hoskisson PA. Novel configurations of type I and I CRISPR-Cas systems in Corynebacterium diphtheriae. Microbiology. 2013; 159(10):2118-26.

61. Blow MJ, Clark TA, Daum CG, Deutschbauer AM, Fomenkov A, Fries R, et al. The epigenomic landscape of prokaryotes. PLoS Genet. 2016;12(2):e1005854

62. Suzuki H. Host-mimicking strategies in DNA methylation for improved bacterial transformation. In: Methylation-from DNA, RNA and histones to diseases and treatment. London: InTech Open Access Publisher; 2012.

63. Bhaya D, Davison M, Barrangou R. CRISPR-Cas systems in bacteria and archaea: versatile small RNAs for adaptive defense and regulation. Annu Rev Genet. 2011;45:273-97.

64. Makarova KS, Haft DH, Barrangou R, Brouns SJ, Charpentier E, Horvath P, et al. Evolution and classification of the CRISPR-Cas systems. Nat Rev Microbiol. 2011;9(6):467-77.

65. Makarova KS, Wolf YI, Alkhnbashi OS, Costa F, Shah SA, Saunders SJ, et al. An updated evolutionary classification of CRISPR-Cas systems. Nat Rev Microbiol. 2015;13(11):722-36.

66. Mao C, Abraham D, Wattam AR, Wilson MJ, Shukla M, Yoo HS, et al. Curation, integration and visualization of bacterial virulence factors in PATRIC. Bioinformatics. 2014;31(2):252-8.

67. Kolberg M, Strand KR, Graff $P$, Andersson KK. Structure, function, and mechanism of ribonucleotide reductases. Biochimica et Biophysica Acta (BBA)-proteins and. Proteomics. 2004;1699(1):1-34. 
68. Oehlmann W, Auling G. Ribonucleotide reductase (RNR) of Corynebacterium glutamicum ATCC 13032-genetic characterization of a second class IV enzyme. Microbiology. 1999;145(7):1595-604.

69. Torrents E, Roca I, Gibert I. Conynebacterium ammoniagenes class Ib ribonucleotide reductase: transcriptional regulation of an atypical genomic organization in the nrd cluster. Microbiology. 2003;149(4):1011-20.

70. Mowa MB. Function and expression of class I ribonucleotide reductase small subunit-encoding genes in Mycobacterium tuberculosis and Mycobacterium smegmatis (doctoral dissertation). 2009.

71. Yang F, Curran SC, Li LS, Avarbock D, Graf JD, Chua MM, et al. Characterization of two genes encoding the Mycobacterium tuberculosis ribonucleotide reductase small subunit. J Bacteriol. 1997;179(20):6408-15.

72. Nurbo J, Roos AK, Muthas D, Wahlström E, Ericsson DJ, Lundstedt T, et al. Design, synthesis and evaluation of peptide inhibitors of Mycobacterium tuberculosis ribonucleotide reductase. J Pept Sci. 2007:13(12):822-32.

73. Buxton A, Corynebacterium FG. Animal Microbiology. Edinburgh: Blackwell Scientific Publications; 1977. p. 177.

74. Brown CC, Olander HJ, Alves SF. Synergistic hemolysis-inhibition titers associated with caseous lymphadenitis in a slaughterhouse survey of goats and sheep in northeastern Brazil. Can J Vet Res. 1987;51(1):46.

75. Ashburner M, Ball CA, Blake JA, Botstein D, Butler H, Cherry JM, et al. Gene ontology: tool for the unification of biology. Nat Genet. 2000;25(1):25-9.

Ready to submit your research? Choose BMC and benefit from:

- fast, convenient online submission

- thorough peer review by experienced researchers in your field

- rapid publication on acceptance

- support for research data, including large and complex data types

- gold Open Access which fosters wider collaboration and increased citations

- maximum visibility for your research: over $100 \mathrm{M}$ website views per year

At $\mathrm{BMC}$, research is always in progress.

Learn more biomedcentral.com/submissions 